\title{
Timing Decisions in a Multinational Context: Implementing the Amin/Bodurtha Framework
}

\author{
Manfred Frühwirth* \\ Vienna University of Economics and Business Administration, Austria \\ Paul Schneider \\ Vienna University of Economics and Business Administration, Austria \\ Markus S. Schwaiger \\ Austrian Central Bank and Vienna University of Economics and Business \\ Administration, Austria
}

The Amin/Bodurtha framework was developed for the valuation of American-style financial instruments driven by three sources of uncertaintydomestic interest rate risk, foreign interest rate risk and exchange rate risk. The model is not only appropriate for pricing a number of financial derivatives, but also, as we show, for valuing foreign investment projects in the presence of real options. In this paper we propose the most natural directly implementable specification within the Amin/Bodurtha framework that permits all combinations of up and down moves of these three risk factors without restricting volatility functions of the factors or correlations between them. By use of the depth-first algorithm, we can show that this specification is implementable at reasonable computation times (JEL: G13, G31, F30).

Keywords: American-style derivatives, multinational timing decisions, depthfirst algorithm.

\section{Introduction}

Timing decisions in a multinational context, i.e., timing decisions that depend on interest rates in two different countries (to be more precise: currency areas) and on the exchange rate between the two currencies, appear in several forms.

\footnotetext{
* This paper was conducted while Manfred Frühwirth was a visiting professor at the Weatherhead Center for International Affairs at Harvard University in the academic year 2005/2006. The author appreciates the support, resources and opportunities provided by the Weatherhead Center during this time.
}

(Multinational Finance Journal, 2007, vol. 11, no. 3/4, pp. 157-178)

(C) by Multinational Finance Society, a nonprofit corporation. All rights reserved. DOI: $10.17578 / 11-3 / 4-1$ 
One type of these timing decisions is the optimal exercise policy of American-style financial instruments that are derivatives on two term structures of interest rates and the respective exchange rate. There is a large number of such instruments including currency swap options (options to buy/sell a currency swap), currency warrants (long-term options on currencies), currency exchange warrants (American-style warrants granting a cash payment if the spot rate in a specified currency exceeds some strike rate) and (rate) differential or cross-rate swaps exchanging interest and principal in one currency for interest and principal in another currency at a conversion rate fixed at the contract date. Furthermore, American-style interest rate derivatives written on two term structures (i.e., cross-currency caps or floors setting a cap or a floor on the spread between two reference interest rates denominated in different currencies) and several types of structured bonds, like callable currency-linked bonds, the returns of which are determined by changes in exchange rates and interest rates in different countries, can be included here.

The other field where timing decisions in a multinational context are increasingly important is real options in a multinational setting. Real options refer to the freedom of an entrepreneur to take decisions affecting the value of a project based on changes in the environment. In a domestic (one country/currency) environment, the real options technique has assumed a prominent role over the last decades (see, e.g., Dixit and Pindyck [1994] for a detailed overview). Recent literature indicates that the concept of real options is becoming more and more significant also from a macro-economic point of view (see, e.g., Emmons and Schmid [2004] or Dapena [2006]).

One essential type of real options are timing options. They are by definition American-style, such that they can be exercised at any time during the "life" of the project, or Bermudan, i.e., can be exercised at multiple discrete points in time. Timing options in a domestic context are covered by literature in detail: E.g., McDonald and Siegel (1986) or Ingersoll and Ross (1992) analyze the optimal timing of an investment ("waiting to invest" problem). Dixit (1989) analyses the optimal timing of both market entry and market exit. McDonald and Siegel (1985) investigate the option to shut down, i.e., the optimal exit time. Another typical timing option is the optimal timing of an expansion. Also, Frühwirth (2002) investigates a timing decision related to specific tax systems.

In the course of globalization both the number and the importance 
of multinational corporations, foreign direct investments and crosscountry mergers and acquisitions have significantly increased (see Clark and Tunaru [2001], Kim, Lyn and Zychowicz [2003], Dunning and Narula [2004], Bernard, Jensen and Schott [2005], Castellani and Zanfei [2006] and Jain and Vachani [2006]). This also results in a growing significance of real options in an international context (see, e.g., Kenneally and Lichtenstein [2002], Rugman and Li [2005] or Driouchi, Battisti and Bennet [2006]). By this, the valuation of multinational timing options becomes important, both from a company's perspective and from a political economy perspective (see, e.g., Darby et al. [1999]). For instance, foreign direct investments involve the flexibility to choose the timing of investment which requires dealing with the evolution of the domestic term structure, the foreign term structure and the exchange rate. Similarly, the option to abandon or the option to expand a foreign direct investment depend on these three risk sources. Finally, switching options between production in different countries and other forms of operational flexibility of multinational corporations involve multinational timing decisions.

Thus, timing decisions in a multinational context, both with respect to financial derivatives and with respect to real options, require explicit modeling of the interest rate environment in (at least) two countries and the respective exchange rate. For the valuation of interest rate and exchange rate financial derivatives several models have been developed over the last three decades: The models range from modifications of the Black/Scholes model (see Garman and Kohlhagen [1983]) to more sophisticated models that include interest rate risk in two different countries/currencies and exchange rate risk (see Grabbe [1983], Hilliard, Madura and Tucker [1991], Amin and Jarrow [1991] and Ekvall, Jennergren and Näslund [1997]). The models cited above, however, can only be used to value European-style derivatives and are therefore not appropriate for timing decisions. ${ }^{1}$

In order to value American-style financial derivatives subject to

1. Using these continuous-time models for the valuation of timing decisions and American-style or Bermudan claims would only be possible in combination with finite differences, Greens functions, or Monte Carlo Simulations (see Longstaff and Schwartz [2001]). Those methods, however, also have drawbacks: Greens functions are notoriously hard to find. Finite differences become computationally infeasible when applied to multifactor models. The Longstaff/Schwartz simulation algorithm causes problems in the valuation of out-of-money options. In addition, when using discretisation schemes for continuous-time no-arbitrage models one has to be careful not to introduce arbitrage opportunities (see Glasserman and Zhao [2000]). 
domestic term structure risk, foreign term structure risk and exchange rate risk, Amin and Bodurtha (1995) introduce a framework, the strength of which is its very general and broad nature leaving much freedom in specification and implementation. Neither the distributions of interest rates and exchange rates nor the structure of the tree are restricted in the framework. ${ }^{2}$

In this paper, we first show how the Amin/Bodurtha framework can be used not only in connection with financial derivatives but also for real options in a multinational context. Then, we present the most natural specification within the Amin/Bodurtha framework. This specification, in contrast to the formulations existing in literature, permits all combinations of the three factors under consideration and preserves the flexibility in the volatility functions and correlations driving the interest rate and exchange rate dynamics. For this specification we explicitly derive the one-period drift rates for the domestic interest rates, foreign interest rates and exchange rates and we propose an algorithm to implement the model. The use of the depth first algorithm, by economizing on computer memory and thereby increasing the number of possible time steps, enables us to implement this specification with modest computing power.

The paper is structured as follows: section II presents the general Amin and Bodurtha (1995) framework without fixing a specification of the model. Section III matches the two types of timing decisions in a multinational context (American-style financial derivatives on the one hand and multinational real options on the other hand) to this framework and explicitly derives the payoffs for a few examples. Section IV deals with the implementation of the model, presenting our specification, comparing it with the existing specifications and presenting the depth-first algorithm to enable an efficient implementation of our (computationally more demanding) specification. Finally, section V concludes.

\section{The Amin/Bodurtha Framework}

The Amin and Bodurtha (1995) framework considers three sources of risk, namely domestic term structure risk, foreign term structure risk and exchange rate risk, all under the risk-adjusted probability measure $Q$

2. This is an important advantage of the Amin and Bodurtha (1995) framework compared to, e.g., Chang (2001). 
("equivalent martingale measure"). Investors can trade every $h$ years.

Let $S(t)$, denote the exchange rate in units of domestic currency per unit of foreign currency. $S(t)$ evolves according to:

$$
\ln \frac{S(t+h)}{S(t)}=\left[\alpha_{S}(t)+r_{d}(t)-r_{f}(t)\right] h+\sigma_{S}(t) X_{S}(t+h) \sqrt{h}
$$

where $\alpha_{S}(t)$ and $\sigma_{S}(t)$ denote drift and exogenously specified volatility functions, $X_{S}(i h), i=1,2, \ldots \tau$ denotes a sequence of independent random variables with expectation 0 and variance 1 under the riskadjusted probability measure and $r_{d}(t)$ and $r_{f}(t)$ denote the continuously compounded domestic $(d)$ and foreign $(f)$ spot rate at time $t$.

The continuously compounded domestic and foreign forward rates at time $t$ for a duration of $h$ years from time $T$ until time $T+h$, specified on a p.a. basis, are denoted by $f_{d}(t, T)$ and $f_{f}(t, T)$. These forward rates follow the process: ${ }^{3}$

$$
\begin{aligned}
& f_{d}(t+h, T)=f_{d}(t, T)+\alpha_{d}(t, T) h+\sigma_{d}(t, T) X_{d}(t+h) \sqrt{h} \\
& f_{f}(t+h, T)=f_{f}(t, T)+\alpha_{f}(t, T) h+\sigma_{f}(t, T) X_{f}(t+h) \sqrt{h}
\end{aligned}
$$

where $\alpha_{d}(t, T)$ and $\alpha_{f}(t, T)$ as well as $\sigma_{d}(t, T)$ and $\sigma_{f}(t, T)$ are functions representing the drift and the exogenously specified volatility of the forward rates and $X_{d}(i h)$ and $X_{f}(i h), i=1,2, \ldots \tau$ denote sequences of independent random variables with expectation 0 and variance 1 under $Q$. Each random variable by definition influences forward rates of all possible maturities. For both currencies, the spot interest rate is defined as the one-period forward rate, thus $r_{d}(t)=f_{d}(t, t)$ and $r_{f}(t)=f_{f}(t, t)$.

Furthermore, the correlation matrix between $X_{d}(t), X_{f}(t)$ and $X_{S}(t)$ is defined by:

3. Note that in the general Amin and Bodurtha (1995) framework all drift and volatility functions as well as correlation coefficients can depend on time as well as past and current state variables. For notational convenience and without loss of generality we omit in this paper in the drift and volatility functions $\alpha_{d}(t, T), \sigma_{d}(t, T), \alpha_{f}(t, T), \sigma_{f}(t, T), \alpha_{S}(t)$ and $\sigma_{S}(t)$ any possible dependence on the state variables, i.e., the forward rates or the exchange rate. The same is true for all correlations used in this paper, which can depend on the point in time and on the state. Of course, empirical estimation can be considerably simplified by assuming a time and state independent correlation matrix. 


$$
\left[\begin{array}{ccc}
1 & \rho_{d f} & \rho_{d S} \\
\rho_{d f} & 1 & \rho_{f S} \\
\rho_{d S} & \rho_{f S} & 1
\end{array}\right]
$$

Within this setting, Amin/Bodurtha derive (cumulative) drift rates valid for all models within their framework.

$$
\begin{aligned}
& {\left[\sum_{i=\frac{t}{h}+1}^{\frac{T}{h}} \alpha_{d}(t, i h) h\right] h=} \\
& \ln \left[E_{t}\left[\exp \left(\left[-\sum_{i=\frac{t}{h}+1}^{\frac{T}{h}} \sigma_{d}(t, i h) h\right] X_{d}(t+h) \sqrt{h}\right)\right]\right] \\
& {\left[\sum_{i=\frac{t}{h}+1}^{\frac{T}{h}} \alpha_{f}(t, i h) h\right] h=} \\
& \ln \left[E _ { t } \left[\operatorname { e x p } \left[\sigma_{S}(t) X_{S}(t+h) \sqrt{h}-\left[\sum_{i=\frac{t}{h}+1}^{\frac{T}{h}} \sigma_{f}(t, i h) h\right]\right.\right.\right. \\
& \left.\left.\times X_{f}(t+h) \sqrt{h}\right]\right]+\alpha_{S}(t) h \\
& \alpha_{S}(t) h=-\ln \left[E_{t}\left[\exp \left[\sigma_{S}(t) X_{S}(t+h) \sqrt{h}\right]\right]\right]
\end{aligned}
$$

where $E_{t}$ denotes the expectation (under $Q$ ) conditional on the information at time $t$.

Equations $3-5$ represent the (cumulative) drift functions of a very general class of models. Different specifications of the tree, i.e., binomial, trinomial or even more complex versions, path-dependent as well as path- 
independent characterisations, with arbitrary volatility functions and arbitrary correlation matrixes for $X_{d}(t), X_{f}(t)$ and $X_{S}(t)$ can be generated.

Based on this, the following steps are required to obtain a readily implementable model:

1. The structure of the tree, i.e., especially the number of nodes departing from each node and the exact distribution of the variables $X_{d}$ $(t), X_{f}(t)$ and $X_{S}(t)$ must be specified.

2. Having determined the structure of the tree, the conditional expectations in equations $3-5$ must be calculated in order to obtain the cumulative drift rates as a function of volatilities and correlations.

3. Afterwards, for practical application, these cumulative drift rates have to be converted into one-period drift rates. This has to be done for any node at any point in time.

4. With the one-period drifts obtained, the next step in the implementation relates to the estimation of the volatility and correlation parameters. This can be done from historical data or implicitly.

5. On this basis the complete tree is constructed by forwardrecursion, using the volatilities and correlations from step 4, as well as the drift terms (as a function of the volatilities and correlations) from step 3 .

6. Then, for each node the payoff of the financial instrument/real option if exercised in this particular node can be determined.

7. Finally, in a standard backward recursive procedure in each node one has to compare the value from immediate exercise with the (conditionally) expected value (under the risk-adjusted probability measure) from optimal later exercise (using the domestic spot interest rates $r_{d}(t)$ for discounting). If the former is higher, then exercise makes sense in this node, otherwise exercise should be postponed to the future optimal exercise time. This yields the value of the financial derivative/real option in each node and the optimal exercise time (stopping time). The value derived is the maximum over all stochastic exercise times of the (risk-adjusted) expected present values of the payoffs at exercise from the instrument. Equally, it can be interpreted as the cost of a dynamic trading strategy that super-replicates the cash flows from the financial derivative/real option. For a definition of superreplication, see Musiela and Rutkowski (1997). For a detailed description of this dynamic programming procedure, see Lamberton and Lapeyre (1996). 


\section{Timing Decisions in a Multinational Context}

Before turning to the implementation of the framework in section IV, we bring, in this section, two relevant and typical examples of timing decisions in a multinational context where the Amin/Bodurtha framework can be used: The first example relates to American-style financial derivatives, for which the Amin/Bodurtha framework originally has been developed. In addition, we show how to extend the field of application of this model to real options that occur in a multinational context. In the following, we derive the payoffs for these two specific examples (i.e., step 6 above).

\section{A. American-Style Financial Derivatives}

As pointed out in the introduction, American-style financial derivatives of the two term structures of interest rate and the exchange rate include currency swap options, currency warrants, currency exchange warrants, (rate) differential or cross-rate swaps, interest rate derivatives written on two term structures like cross-currency caps or floors and structured bonds like callable currency-linked bonds. Theoretically (i.e., not looking at implementational issues), the valuation of each of these instruments using the Amin/Bodurtha framework is straightforward.

Let us investigate, as an example, the valuation of an American-style currency swap option ("currency swaption"). The value of such a derivative is the maximum over all possible stochastic exercise times of the risk-adjusted expected present value of the payoffs from the option at exercise time. Both this maximum value and the optimal exercise time can be derived using the Amin and Bodurtha (1995) model and the seven steps outlined in the previous section.

The first five steps relate to the forward-recursive construction of the tree. These steps are completely independent of the instrument to be valued. In step 6 for each node of the tree, representing the term structures of domestic and foreign interest rates as well as the foreign exchange rate, the payoff of the respective financial instrument if exercised in this node has to be derived. This is the only step that depends on the security. In general, there are different specifications of currency swaptions. Therefore, the precise payoff from the currency swaption is determined in the specific contract.

Let us investigate one particular example of a fixed-for-fixed currency swaption where a currency swap (where the holder receives 
interest payments on a specified notional in domestic currency at a specified domestic interest rate and performs interest payments on a specified notional in foreign currency at a specified foreign interest rate, including the exchange of the notional at the end) can be purchased at a given strike price. Using for the maturity of the swap the symbol $T$, for the domestic currency notional the symbol $N_{D}$, for the foreign currency notional $N_{F}$, for the domestic interest rate of the swap $r_{S, D}$ and for the foreign interest rate $r_{S, F}$, the time $t$-value of the swap from the perspective of the party that receives the payments in domestic currency and pays the foreign currency cash flow is:

$$
\begin{gathered}
V_{S W A P}(t)=N_{D} r_{S, D} \sum_{s=\frac{t}{h}+1}^{\frac{T}{h}} \exp \left[-\sum_{u=\frac{t}{h}}^{S-1} f_{d}(t, u h) h\right]-S(t) N_{F} r_{S, F} \\
\times \sum_{s=\frac{t}{h}+1}^{\frac{T}{h}} \exp \left[-\sum_{u=\frac{t}{h}}^{s-1} f_{f}(t, u h) h\right]+N_{D} \exp \left[-\sum_{u=\frac{t}{h}}^{\frac{T}{h}-1} f_{d}(t, u h) h\right] \\
-S(t) N_{F} \exp \left[-\sum_{u=\frac{t}{h}}^{\frac{T}{h}-1} f_{f}(t, u h) h\right]
\end{gathered}
$$

Due to the completeness of the market (see, e.g., Dothan [1990] for the concept of market completeness), $V_{S W A P}(t)$ can be interpreted as the cost of a trading strategy that replicates the cash flows from the swap. Based on $V_{S W A P}(t)$, the payoff of a call option on the swap with exercise price $K$ if exercised at time $t$ is:

$$
V_{C A L L}(t)=\operatorname{MAX}\left[V_{S W A P}(t)-K, 0\right]
$$

The final step 7 (backward recursive valuation of the American-style derivative) is again identical for all securities and described in the previous section.

\section{B. Real Options in a Multinational Context}

The Amin/Bodurtha framework, in general, can be used for all timing 
options that depend on the interest rate and exchange rate development. An important field of application is the valuation of flexibility and optimal timing decisions of multinational companies that are active in more than one currency area. The most popular examples are the option to invest abroad (in a foreign direct investment or more general any investment project (e.g., a subsidiary) that generates cash flows in a foreign currency), i.e., the optimal timing of market entry, or the option to abandon a (foreign direct) investment in another currency area, i.e., the optimal timing of a market exit. ${ }^{4}$

The procedure for the valuation of timing options in a multinational context is very similar to the valuation of American-style financial derivative described in III.A. Both the building of the tree and the backward recursive valuation are identical. The only difference is step 6 where the payoff of the real option in each node is determined.

Let us explain this step with the example of the option to invest abroad, i.e., the optimal timing of an FDI market entry. The criterion for the decision-maker is to maximize (over all possible stochastic exercise times) the expected net present value (under the risk-adjusted probability measure), as of time 0 , in the domestic currency. The methodology for both optimization of market entry timing and valuation of this flexibility is the standard backward recursion in the Amin/Bodurtha tree.

Assuming that the cash flows in the foreign currency at each time

4. Generally speaking, multinational timing decisions inevitably create an Americanstyle option or Bermudan option that depend on these three factors in combination. One could of course ask, why a three-factor derivatives model is required for these decisions and whether any simplifications are possible. One argument could be that if all the cash flows (including the cost) are given in foreign currency, modeling only the foreign term structure of interest rates, optimizing in the foreign term structure tree and converting the NPV at the spot exchange rate would be sufficient. However, modeling only the foreign term structure would be only sufficient if the goal was to maximize the net present value in foreign currency. Due to the stochastic exercise time an optimization in the foreign currency and a conversion at the spot exchange rate does not give the same results as the optimization in the domestic currency using the three-factor model as described at the end of section II. Furthermore, modeling foreign currency cash flows that depend on domestic interest rate risk or exchange rate risk inevitably requires explicit modeling of these two factors, as well. Another simplification would involve the (unrealistic) assumption of independence of exchange rate, domestic interest rates and foreign interest rates. By this, one could reduce complexity in the computation of the expected present values of the cash flows-given an exercise time (e.g., working with the current forward exchange rate, to convert the stream of foreign currency cash flows into domestic currency cash flows, or with the current domestic term structure instead of the successive discounting with the future spot rates). But even in this case, finding the optimal exercise time involves optimization over all stochastic exercise times in the tree. 
step $s(t<s h \leq T)$, symbolized by $C F(s h)$, only depend on the interest and exchange rate environment at or before time $s h$, the present value of the FDI as of time $t$ in domestic currency, $P V(t)$, is represented by the following equation: ${ }^{5}$

$$
P V(t)=\sum_{s=\frac{t}{h}+1}^{\frac{T}{h}} E_{t}\left[C F(s h) S(s h) \exp \left[-\sum_{u=\frac{t}{h}}^{s-1} r_{d}(u h) h\right]\right]
$$

The option to invest abroad is simply a call option on this present value of the investment project. Therefore, using $C(t)$ for the cost of the FDI in domestic currency at time $t$, the payoff of the real option if exercised at $t$ is:

$$
V_{\text {OPTION }}(t)=\operatorname{MAX}[P V(t)-C(t), 0]
$$

In a similar way, the option to abandon a foreign investment can be represented as a put option on the foreign investment with the present value standing for the value of all cash flows yet to come and using instead of the cost of the project the proceeds from abandoning the foreign investment.

Note that by using the original Amin/Bodurtha framework for multinational timing options one does not necessarily implicitly assume deterministic cash flows. Both the cash flows $C F(t)$ and the cost $C(t)$ can depend on the domestic and foreign term structure of interest rates and the exchange rate, at or before time $t$. Especially, if the cost of a foreign investment is expressed (or negotiated) in foreign currency, it is plausible that $C(t)$, the cost in domestic currency, depends on the exchange rate $S(t)$. Thus, the underlying assumption is that cash flows

5. In contrast to equation 6 where we could discount the foreign cash flows using the foreign term structure as of time $t$ and convert the foreign currency present value into the domestic currency present value using the exchange rate at time $t$, here we have to convert the cash flow in foreign currency at time $s h$ into domestic currency using the exchange rate at time $s h$, then discount by the series of domestic spot rates and finally take the risk-adjusted expectation. The reason for this discrepancy is that in equation 6 all cash flows were known as of time $t$ (measurable with respect to the time- $t$ sigma field), which is not the case in equation 8 , as we also want to allow foreign currency cash flows that are correlated with the interest rate and exchange rate environment. With foreign currency cash flows independent of interest rates and exchange rates, a discounting analogous to equation 6 would be possible. 
are only subject to interest rate and exchange rate risk (or can be spanned by these three risk factors) and that there is no idiosyncratic cash flow risk, i.e., risk in addition to interest rate and exchange rate risk. It must be highlighted that the absence of such an idiosyncratic risk factor is frequently assumed in the waiting to invest literature in a domestic context (e.g., Ingersoll and Ross [1992]) or other timing options that exist in a domestic context (e.g., Frühwirth [2002]). Neglecting idiosyncratic cash flow risk seems justified especially for FDI in financial companies abroad, as for financial companies interest rate risk and exchange risk represent a large bulk of the risk (see Guo and $\mathrm{Wu}$ [1998] for an empirical study of the impact of exchange rates on the value of firms). From a modeling perspective, the important benefit of this assumption of no idiosyncratic risk is that the market is complete which means that all risk can be hedged by trading bonds denominated in the two currencies as well as foreign exchange.

On the other hand, one could argue that timing decisions also depend on an idiosyncratic cash flow risk factor (e.g., changing demand). If one does not want to neglect such an idiosyncratic cash flow risk factor, one has to use a fourth stochastic factor, that represents idiosyncratic cash flow risk. This would demand a generalization of the Amin and Bodurtha (1995) model, as developed, e.g., by Wang (1999) or Chung and Yang (2005) for the valuation of financial derivatives. It goes without saying that using a four factor model instead of the original three factor Amin/Bodurtha model would increase complexity. In this case, the efficiency increasing measures in implementation we describe in the following section are even more important. It can be shown that these efficiency increasing measures result in a similar relative increase in efficiency also for reductions (e.g., to two factors) and generalizations (to more than three factors) of the Amin/Bodurtha model. It must be added, however, that the whole procedure both with and without the efficiency increasing measures takes longer with a fourth factor, which can be considered as the price for integrating additional idiosyncratic cash flow risk. ${ }^{6}$

6. Note that with a fourth factor, unless there is an additional security that spans the market, completeness of the market gets lost which is a problem of real options literature that is not unique to our paper. In this case, a sound solution requires the assumption that cash flow risk is completely uncorrelated with the market portfolio (which allows discounting by the risk-free domestic interest rate) or a technique described in the incomplete market literature (e.g., a methodology based on utility functions as can be seen from Föllmer and Schweitzer [1991] or other techniques as listed in Musiela and Rutkowski [1997]). 


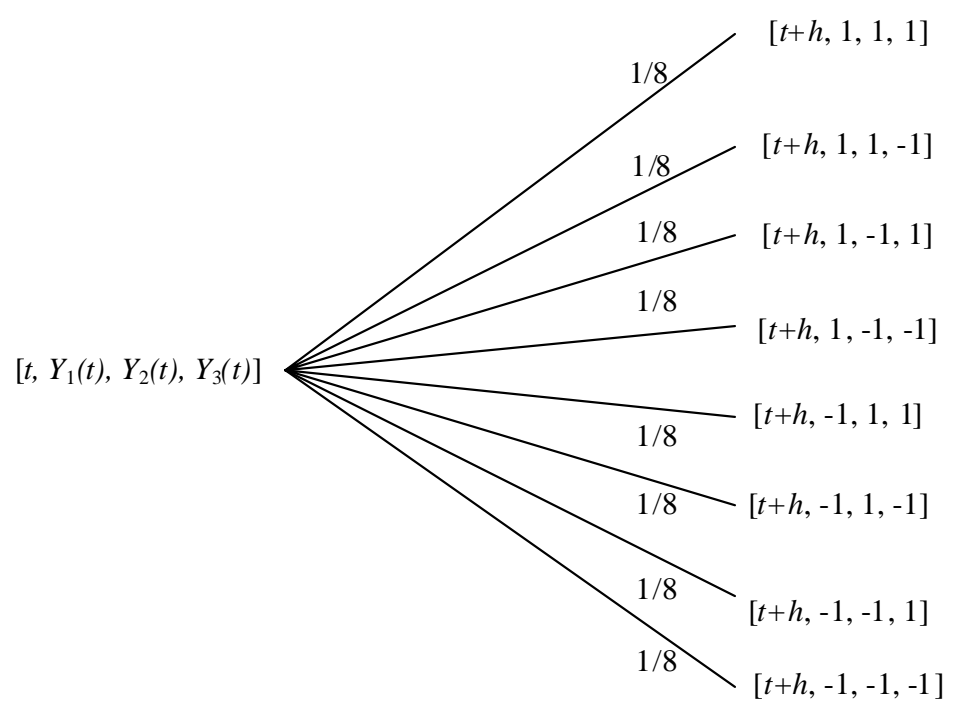

FIGURE 1-A Segment of the Generated Tree a risk-adjusted

\section{Implementation of the Amin/Bodurtha Framework}

Given two specific examples of the application of the Amin/Bodurtha framework, we now want to turn to some issues related to the implementation.

\section{A. Tree Structure}

With regard to the tree structure, Amin and Bodurtha (1995) propose two alternative specifications. The "eight-node path-independent model" uses eight nodes but assumes volatilities to be constant. As drift terms from the continuous-time models of Amin and Jarrow (1991, 1992) are substituted for the drift terms in the discrete-time model of Amin/Bodurtha (see Amin and Bodurtha [1995], p. 206), it represents only an approximation. In the second tree structure, the "four-node model," each node is followed by four nodes. $X_{d}$ and $X_{f}$ are modeled explicitly, $X_{S}$ is a function of $X_{d}$ and $X_{f}$ (see Amin and Bodurtha [1995], p. 202 and p. 204ff). Both existing specifications thus impose restrictions: Besides using approximations from the continuous-time 
model, the eight-node path-independent model strongly restricts volatilities. Furthermore, this specification can no longer be used to price path-dependent (Asian) derivatives. In the four-node model not all combinations of ups and downs of the three factors are possible. An increase in the first two factors $X_{d}$ and $X_{f}$ for instance automatically implies an increase in the third factor $X_{S}$.

The most natural model specification would however be one that allows any combination of up and down moves of the three factors under consideration as well as arbitrary volatility functions. Elements of the two model specifications proposed by Amin/Bodurtha can be combined to achieve this. To begin with, we borrow the assumption of a risk-adjusted probability of $1 / 2$ for both states from the Amin/Bodurtha four-node-model. From the eight-node path-independent model we adopt the suggestion to replace the correlated random variables $X_{d}(t), X_{f}(t)$ and $X_{S}(t)$ by linear combinations of mutually independent random variables $Y_{1}(t), Y_{2}(t)$ and $Y_{3}(t)$. $X(t)$ and $Y(t)$ are related to each other by:

$$
\begin{gathered}
X_{d}(t)=Y_{1}(t) \\
X_{f}(t)=\rho_{d f} Y_{1}(t)+\sqrt{1-\rho_{d f}^{2}} Y_{2}(t) \\
X_{S}(t)=\rho_{d S} Y_{1}(t)+\bar{\rho}_{f s} Y_{2}(t)+\sqrt{1-\rho_{d S}^{2}-\bar{\rho}_{f s}^{2}} Y_{3}(t)
\end{gathered}
$$

where $\bar{\rho}_{f S}=\rho_{f S}-\left(\rho_{d f} \rho_{d S} / \sqrt{1-\rho_{d f}^{2}}\right)$.

In addition, we assume that each $Y(t)$ can either move up $(Y(t)=1)$ or down $(Y(t)=-1)$.

In the resulting specification, eight nodes at time $t+h$ follow each node at time $t$. This model therefore allows any combination of up and down moves of the three factors under consideration. In addition, it can be shown that with this specification the Amin/Bodurtha restrictions on expectation, variance and correlation are fulfilled $\left(E\left[X_{d}\right]=E\left[X_{f}\right]=\right.$ $E\left[X_{S}\right]=0, V\left[X_{d}\right]=V\left[X_{f}\right]=V\left[X_{S}\right]=1, \operatorname{CORR}\left[X_{d}, X_{f}\right]=\rho_{d f}, \operatorname{CORR}\left[X_{d}\right.$, $\left.\left.X_{S}\right]=\rho_{d S}, \operatorname{CORR}\left[X_{f}, X_{S}\right]=\rho_{f S}\right)$. Figure 1 illustrates the tree, with the vector $\left(t, Y_{1}(t), Y_{2}(t), Y_{3}(t)\right)$ denoting the values of the respective random variables at time $t$. 


\section{B. One-Period Drift Rates}

Following steps 2 and 3 of the seven steps outlined in section II, all oneperiod drift rates to build the tree for this model have to be calculated to obtain a readily implementable model specification. Analytically this is achieved by replacing $X_{d}(t+h)$ in equation 3 by $Y_{1}(t+h)$ and computing the conditional expectation. Subtracting the cumulative drift rate for a time horizon of $T-h$ from the cumulative drift rate for a time horizon of $T$ and using $\cosh [x]=0.5(\exp [x]+\exp [-x])$ yields for all $t$ and $T$ the one-period drift rates:

$$
\alpha_{d}(t, T)=\frac{1}{h^{2}} \ln \left[\frac{\cosh \left[\sum_{i=\frac{t}{h}+1}^{\frac{T}{h}} \sigma_{d}(t, i h) \sqrt{h} h\right]}{\cosh \left[\sum_{i=\frac{t}{h}+1}^{\frac{T}{h}-1} \sigma_{d}(t, i h) \sqrt{h} h\right]}\right]
$$

In analogy to that we can obtain the one-period drift rates for the foreign forward rate dynamics and the exchange rate dynamics. To obtain $\alpha_{S}(t), X_{S}(t+h)$ in equation 5 has to be replaced by the corresponding function as defined in equation 12. The next step involves splitting up the expectation into the product of the expectations of independent random variables. Calculating expectations and using the definition of the cosinus hyperbolicus again yields the final expression for the drift term of the exchange rate dynamics at any time $t$ :

$$
\begin{aligned}
\alpha_{S}(t)=- & \frac{1}{h} \ln \left[\cosh \left[\sigma_{S}(t) \sqrt{h} \rho_{d S}\right] \cosh \left[\sigma_{S}(t) \sqrt{h} \bar{\rho}_{f S}\right]\right. \\
& \left.\times \cosh \left[\sigma_{S}(t) \sqrt{h} \sqrt{1-\rho_{d S}^{2}-\bar{\rho}_{f S}^{2}}\right]\right]
\end{aligned}
$$

In order to compute the drift term for the foreign interest rate dynamics, $X_{f}(t+h)$ and $X_{S}(t+h)$ in equation 4 have to be replaced by the respective functions in equations 11 and 12. Splitting up the expectation into the product of the expectations of independent random 
variables and solving for the drift at time $t$ for maturity $T$ leads to: ${ }^{7}$

$$
\begin{gathered}
\alpha_{f}(t, T)=\frac{1}{h^{2}} \ln \left[\frac{\cosh \left[\sigma_{S}(t) \rho_{d S} \sqrt{h}-\sum_{i=\frac{t}{h}+1}^{\frac{T}{h}} \sigma_{f}(t, i h) \rho_{d f} \sqrt{h} h\right]}{\cosh \left[\sigma_{S}(t) \rho_{d S} \sqrt{h}-\sum_{i=\frac{t}{h}+1}^{\frac{T}{h}-1} \sigma_{f}(t, i h) \rho_{d f} \sqrt{h} h\right]}\right. \\
\left.\times \frac{\cosh \left[\sigma_{S}(t) \bar{\rho}_{f S} \sqrt{h}-\sum_{i=\frac{t}{h}+1}^{\frac{T}{h}} \sigma_{f}(t, i h) \sqrt{1-\rho_{d f}^{2}} \sqrt{h} h\right]}{\operatorname{Tos}_{h}-1}\right] \\
\cosh \left[\sigma_{S}(t) \bar{\rho}_{f S} \sqrt{h}-\sum_{i=\frac{t}{h}+1}^{h} \sigma_{f}(t, i h) \sqrt{1-\rho_{d f}^{2}} \sqrt{h} h\right]
\end{gathered}
$$

In line with the intuition built up by numerous authors since Black and Scholes (1973), the drift terms in 13, 14 and 15 only depend on volatilities and correlations. Furthermore, we derived these drift terms only by specifying the number of nodes, the values of the independent random variables $Y(t)$ as well as the probabilities-fulfilling the restrictions of Amin/Bodurtha.

\section{Comparison with Existing Specifications}

Let us compare the specification presented so far to those existing in literature: As opposed to the four-node model proposed by Amin/Bodurtha, in our specification $X_{S}$ is explicitly modeled and not implicitly as a function of $X_{d}$ and $X_{f}$, so that all combinations of ups and downs of the three factors are possible.

As opposed to the eight-node path-independent model proposed by Amin/Bodurtha, in our model specification there are no restrictions on variances or covariances, which opens the way for numerous models: e.g., the domestic/foreign term structure dynamics can be modeled by

7. The detailed derivation of $\alpha_{f}(t, T)$ is more tedious than in the previous two cases and can be obtained from the authors upon request. 
means of a Ho and Lee (1986) constant volatility model (i.e., $\sigma(t, T)=$ $\sigma$ ), the exponentially decaying variance model (i.e., $\sigma(t, T)=\sigma \exp [-\lambda x$ $(T-t)]$ ), as shown by Heath, Jarrow and Morton (1992) or the constant elasticity of variance model (i.e., $\sigma(t, T)=\sigma f(t, T)^{\alpha}$ ) proposed by Cox and Ross (1976). Recent research in continuous-time modeling of interest rates (see Ait-Sahalia [1996] or Jones [2003]) investigates more sophisticated volatility functions such as $\sigma(t, T)=\sqrt{\beta_{0}+\beta_{1} f(t, T)+\beta_{2} f(t, T)^{\beta_{3}}}$. Even these volatility functions can be integrated into the model specification derived above. To model the exchange rate dynamics a constant volatility model or a constant elasticity of variance model can be used, to give a few examples.

Thus, with the model specification presented in the previous subsections, in contrast to the eight-node path-independent model also stochastic volatility functions can be included. Stochastic volatility in interest rate markets is a stylized fact that is widely recognized in the empirical literature. Many stochastic volatility functions have the additional advantage that they prevent (or at least strongly reduce the probability of) negative interest rates (see, e.g., Cox, Ingersoll and Ross [1985], Heath, Jarrow and Morton [1992] or Amin and Morton [1994]). Also, including ARCH/GARCH effects inevitably leads to stochastic volatilities (see, e.g., Kuberek [1992] or Gray [1996] for ARCH/GARCH models for interest rates).

Another argument speaking for the model specification shown above (compared to the eight-node path-independent model) is that pathdependent products (e.g., Asian products) can be valued.

It goes without saying that a path-dependent eight-node model is computationally less efficient than both a four-node model and a pathindependent eight-node model. This loss of efficiency, however, represents the price to be paid for the opportunity to use all combinations of ups and downs of the three factors and non-constant, even unrestricted, volatilities. The next section shows how to keep this loss of efficiency small.

\section{Depth-first Algorithm}

The reason for the restrictive assumptions in the two specifications existing in literature was to reduce complexity in order to enable a reasonable implementation. As a matter of fact the tree described above 
produces an exponentially growing number of nodes. A simple calculation of the number of nodes that have to be kept in memory for 10 time steps gives $1,227,133,513$ nodes. This implies exponentially growing calculation times and memory requirements that at this point can not be satisfied even by the most sophisticated computers. Given that each node contains two complete forward rate curves in addition to an exchange rate evolution it is clear that using a path-dependent model specification severely restricts the number of feasible time steps.

To solve the memory problem we suggest using the depth-first algorithm as described in Broadie and Glasserman (1997). The depthfirst algorithm exploits the fact that different branches can be computed independently of each other. The storage requirement of the depth-first algorithm is a $b x d$ matrix only, where $b$ is the number of states and $d$ is the number of time steps. In addition to minimal storage needs, the depth-first algorithm grants memory access to array data structures which is usually faster than with tree structures.

In the following, we apply the depth-first algorithm with a timeindependent and state-independent correlation matrix by using two different volatility settings: The first setting is one with purely deterministic volatility functions, namely the exponentially decaying volatility model for interest rate volatility and a constant volatility for the exchange rate volatility $\left(\sigma_{d}(t, T)=\sigma_{d} \exp \left[-\lambda_{d}(T-t)\right], \sigma_{f}(t, T)=\right.$ $\left.\sigma_{f} \exp \left[-\lambda_{f}(T-t)\right], \sigma_{S}(t)=\sigma_{S}\right)$. The second setting is based on stochastic volatility functions. We use the constant elasticity of variance process for all three components $\left(\sigma_{d}(t, T)=\sigma_{d} f_{d}(t, T)^{\alpha}, \sigma_{f}(t, T)=\sigma_{f} f_{f}(t, T)^{\beta}\right.$, $\left.\sigma_{S}(t)=\sigma_{S} S(t)^{\gamma}\right)$.

Table 1 shows the time to build the tree and price a financial instrument or real option. ${ }^{8}$ In total, for $x$ periods $\sum_{i=0}^{x} 8^{i}$ nodes have to be
evaluated. ${ }^{9}$ Time is denoted in seconds.

The computation times in table 1 show that for a sufficiently large numbers of periods, pricing with our eight-node path-dependent model specification is possible at acceptable computation times both with deterministic volatility functions and with stochastic volatility functions. Note that with the pruning techniques described in Gautam,

8. The model was implemented in $\mathrm{C}++$ and compiled with the gec 3.3.1 package with flags $-\mathrm{O} 3-\operatorname{march}=$ pentium $4-\mathrm{mcpu}=$ pentium $4-\mathrm{msse}-\mathrm{msse} 2-\mathrm{mmmx}$. The calculations were performed on a standard Pentium 4 Linux machine.

9. A period number of $x$ requires a tree depth of $x+1$, because we assume to start at time $t=0$. 
TABLE 1. Computation Time Analysis (Time in Seconds)

\begin{tabular}{ccr}
\hline $\begin{array}{c}\text { Number } \\
\text { of Periods }\end{array}$ & $\begin{array}{c}\text { Computation Time } \\
\text { (Deterministic Volatility } \\
\text { Functions) }\end{array}$ & $\begin{array}{c}\text { Computation Time } \\
\text { (Stochastic Volatility } \\
\text { Functions) }\end{array}$ \\
\hline 4 & 0.0000 & 0.0400 \\
5 & 0.0300 & 0.2500 \\
6 & 0.2300 & 2.0100 \\
7 & 1.8100 & 16.4300 \\
8 & 14.5700 & 129.9200 \\
9 & 115.2300 & 1024.5400 \\
10 & 929.3700 & 8340.3400 \\
\hline
\end{tabular}

Broadie and Glasserman (1997) even further speed increases can be obtained. Therefore, neither a reduction to a four-node model nor a restriction of volatility functions to obtain a path-independent eightnode model is necessary with today's computing capacity using the depth-first algorithm.

\section{Conclusion}

The Amin and Bodurtha (1995) framework can be applied for many types of multinational timing decisions, both in the valuation of American-style financial derivatives and in the valuation of real options in a multinational context. The purpose of this paper is to present a readily implementable model specification within the Amin/Bodurtha framework. As its main benefits, compared to existing specifications in literature, this model specification allows any combination of up and down moves of the three factors (domestic interest rate risk, foreign interest rate risk and exchange rate risk) as well as arbitrary volatility functions. We derive closed-form solutions for the one-period drift rates of the three factors in this model specification. We furthermore demonstrate that the problem of increased computational complexity can be remedied by means of the depth-first algorithm. Pricing with our model specification is possible at acceptable computation times for a sufficiently large number of periods. Thus, the simplified and more restrictive specifications suggested by Amin/Bodurtha are no longer necessary using the depth-first algorithm. 


\section{References}

Ait-Sahalia, Y. 1996. Testing continuous-time models of the spot interest rate. Review of Financial Studies 9: 385-426.

Amin, K. I., and Bodurtha, J. N. 1995. Discrete-time valuation of American options with stochastic interest rates. Review of Financial Studies 8 (1): 193-234.

Amin, K. I., and Jarrow, R. A. 1991. Pricing foreign currency options under stochastic interest rates. Journal of International Money and Finance 10: 310-330.

Amin, K. I., and Jarrow, R. A. 1992. Pricing options on risky assets in a stochastic interest rate economy. Mathematical Finance 2: 217-238.

Amin, K. I., and Morton, A. J. 1994. Implied volatility functions in arbitragefree term structure models. Journal of Financial Economics 35: 141-180.

Bernard, A. B.; Jensen, J. B.; and Schott, P. K. 2005. Importers, exporters and multinationals: A portrait of the firms in the U.S. that trade goods. NBER working paper no. 11404. Cambridge, Mass.: National Bureau of Economic Research.

Black, F., and Scholes, M. 1973. The pricing of options and corporate liabilities. Journal of Political Economy 81: 637-659.

Broadie, M., and Glasserman, P. 1997. Pricing American-style securities using simulation. Journal of Economic Dynamics and Control 21: 1323-1352.

Castellani, D., and Zanfei, A. 2006. Multinational Firms, Innovation and Productivity. Cheltenham: Edward Elgar Publishing.

Chang, C.-C. 2001. Efficient procedures for the valuation and hedging of American currency options with stochastic interest rates. Journal of Multinational Financial Management 11: 241-268.

Clark, E., and Tunaru, R. 2001. Emerging markets: Investing with political risk. Multinational Finance Journal 5: 155-173.

Chung, S.-L., and Yang, H.-F. 2005. Pricing quanto equity swaps in a stochastic interest rate economy. Applied Mathematical Finance 12: 121-146.

Cox, J. C.; Ingersoll, J. E.; and Ross, S. A. 1985. A theory of the term structure of interest rates. Econometrica 53: 385-407.

Cox, J. C., and Ross, S. A. 1976. The valuation of options for alternative stochastic processes. Journal of Financial Economics 3: 145-166.

Darby, J.; Hallett, A.; Ireland, J.; and Piscitelli, L. 1999. The impact of exchange rate uncertainty on the level of investment. The Economic Journal 109: C55-C67.

Dapena, J. 2006. Volatility of GDP, macro applications and policy implications of real options. Working paper. Buenos Aires: Universidad del CEMA.

Dixit, A., and Pindyck, R. 1994. Investment under Uncertainty. Princeton: Princeton University Press.

Dixit, A. 1989. Entry and exit decisions under uncertainty. Journal of Political Economy 97: 620-638. 
Dothan, M. 1990. Prices in Financial Markets. New York: Oxford University Press.

Driouchi, T.; Battisti, G.; and Bennet, D. 2006. Multinationality and real options: Empirical evidence. Working paper. Birmingham: Aston Business School.

Dunning, J., and Narula, R. 2004. Multinationals and Industrial Competitiveness. Cheltenham: Edward Elgar Publishing.

Ekvall, N.; Jennergren, P. L.; and Näslund, B. 1997. Currency option pricing with mean reversion and uncovered interest parity: A revision of the Garman-Kohlhagen model. European Journal of Operational Research 100: 41-59.

Emmons, W., and Schmid, F. 2004. Monetary policy actions and the incentive to invest. Business Economics 39 (2): 24-30.

Föllmer, H., and Schweitzer, M. 1991. Hedging of contingent claims under incomplete information. In M. H. A. Davis and R. J. Elliot (eds.). Applied Stochastic Analysis - Stochastic Monographs 5. London: Gordon and Breach.

Frühwirth, M. 2002. The optimal timing of the transfer of hidden reserves in the German and Austrian tax systems. International Journal of Intelligent Systems in Accounting, Finance \& Management 11 (2): 71-88.

Garman, M. B., and Kohlhagen, S. W. 1983. Foreign currency option values. Journal of International Money and Finance 2: 231-237.

Gautam, J.; Broadie, M.; and Glasserman, P. 1997. Enhanced Monte Carlo estimates for American option prices. Journal of Derivatives 5 (1): 25-44.

Glasserman, P., and Zhao, X. 2000. Arbitrage-free discretization of log-normal forward LIBOR and swap rate models. Finance and Stochastics 4: 35-68.

Grabbe, J. O. 1983. The pricing of call and put on foreign exchange. Journal of International Money and Finance 2: 239-253.

Gray, S. 1996. Modeling the conditional distribution of interest rates as a regime-switching process. Journal of Financial Economics 42: 27-62.

Guo, J., and Wu, R. 1998. Financial liberalization and the exchange rate exposure of the Taiwanese firms: A nonparametric analysis. Multinational Finance Journal 2: 37-61.

Heath, D.; Jarrow, R. A.; and Morton, A. 1992. Bond pricing and the term structure of interest rates: A new methodology. Econometrica 60: 77-105.

Hilliard, J.; Madura, J.; and Tucker, A. 1991. Currency option pricing with stochastic domestic and foreign interest rates. Journal of Financial and Quantitative Analysis 26 (2): 139-151.

Ho, T. S. Y., and Lee, S.-B. 1986. Term structure movements and pricing interest rate contingent claims. Journal of Finance 41: 1011-1029.

Ingersoll, J. E., and Ross, S. A. 1992. Waiting to invest: Investment and uncertainty. Journal of Business 65 (1): 1-29.

Jain, S., and Vachani, S. 2006. Multinational Corporations and Global Poverty Reduction. Cheltenham: Edward Elgar Publishing. 
Jarrow, R. A. 1996. Modelling Fixed Income Securities and Interest Rate Options. New York: McGraw-Hill.

Jones, C. 2003. Nonlinear mean reversion in the short-term interest rate. Review of Financial Studies 16: 793-843.

Kenneally, J., and Lichtenstein, Y. 2002. The optional value of IS projects - A study of an IS portfolio at a multinational manufacturer. Proceedings of the 10th European Conference on Information Systems (ECIS): Information Systems and the Future of the Digital Economy. Gdansk (Poland).

Kim, W. S.; Lyn, E.; and Zychowicz, E. 2003. Is the source of FDI important to emerging market economies? Evidence from Japanese and U.S. FDI. Multinational Finance Journal 7: 107-130.

Kuberek, R. 1992. Predicting interest rate volatility: A conditional heteroskedastic model of interest rate movements. Journal of Fixed Income 1: 21-27.

Lamberton, D., and Lapeyre, B. 1996. Introduction to Stochastic Calculus Applied to Finance. London: Chapman \& Hall.

Longstaff, F., and Schwartz, E. 2001. Valuing American options by simulation: A simple least squares approach. Review of Financial Studies 14 (1): 113-147.

McDonald, R., and Siegel, D. 1985. Investment and valuation of firms when there is an option to shut down. International Economic Review 26: 331-349.

McDonald, R., and Siegel, D. 1986. The value of waiting to invest. Quarterly Journal of Economics 101 (4): 707-727.

Musiela, M., and Rutkowski, M. 1997. Martingale Methods in Financial Modeling. Berlin: Springer.

Rugman, A., and Li, J. 2005. Real Options and International Investment. Cheltenham: Edward Elgar Publishing.

Wang, M.-C. 1999. The pricing of cross currency equity swaps and swaptions, PhD-Dissertation, New York: New York University. 